\title{
İngilizce Kelime Öğretimine Bir Bakış: Renklerin Kullanımı
}

\author{
A View to English Vocabulary Teaching: The Use of Colours \\ İran TOSUNCUOĞLU \\ Doç. Dr., Karabük Üniversitesi \\ Makale Başvuru Tarihi / Received: 29.11.2020 \\ irtosun@yahoo.com \\ Makale Kabul Tarihi / Accepted: 06.12.2020 \\ Makale Türü / Article Type: Araştırma Makalesi
}

https://orcid.org/ 0000-0002-0213-3574

\begin{abstract}
Anahtar
Kelimeler:

ÖZET

Ingiliz dili

ögretimi,

Dünyanın iletișim ve bilim dili hâline gelen İngilizcenin bilinmesi günümüz şartlarında artık önemli bir ihtiyaç olarak görülmektedir. Demirel'in (2019) de bahsettiği gibi iletiş̧im kurma ihtiyacı, bilim ve teknikteki hizl ilerleme ve gelişmeler, ekonomik, sosyal ve kültürel ilişkiler yetkin bir şekilde yabancı dil bilme gerekliliğini doğurmuştur. Günümüzde özellikle uluslararası ticarette çok yaygın olarak kullanılmakta

Renkler, olan Ingilizce, bilimsel alanda da ortak dil olarak yaygın bir hâle gelmiştirr. Uluslararası kabul görmüs birçok bilimsel dergi makalelerini İngilizce yayımlamaktadır. Ingilizce artık küreselbir dil olarak görülmeye

Ögrenciler başlanmıştır. Son yıllarda İngilizce öğretimi ile ilgili üzerinde durulan başlıca konulardan birisi de "kelime öğretimi” konusudur. Pek çok öğrenci kelime öğrenmenin zor olduğunu düşünmektedir. Bireylerin

Öğretmenler, sahip olduğu kelime bilgisinin hedeflenen dildeki becerileri etkili bir şekilde kullanmayı doğrudan etkilediğinden dolayı bu husus çok önemli bir konudur. Genel anlamda kelimeler bir dilin yapı taşlarını

Kelime oluşturmaktadır. Herhangi basit ricadan çok kompleks yapıdaki duygu ve düşünceler kelimeler vasıtasıyla anlatılır. Bu nedenle kelime öğretimi, dil öğretiminin temel yapı taşlarından sayılmaktadır. Renk kavramı doğada gördüğ̈̈müz her nesnede karşımıza çıkmakta ve duygusal olarak bizi etkilediği gibi duygularımızı anlatmada da bir araç olarak kullanılmaktadır. Özellikle Görsel zekâya sahip bireyler başta olmak üzere ögrrenciler, renklere karşı hassas ve duyarlıdır. Bu sebeple İngilizce ögrretim materyâllerinde renklerden yaralanılmaktadır. Buradan yola çıkarak kelime öğretiminde renklerin kullanımı çalışmada incelennmiştir.
\end{abstract}

Keywords:

English language teaching,

Colours,

Students,

Teachers,

Vocabulary

\begin{abstract}
Knowledge of English, which has become the communication and science language of the world, is now seen as a significant requirement in today's world. As Demirel (2019) mentioned, the rapid progress and developments in science and technology after the Second World War have led to the requirements for proficient foreign language knowledge. English, which is widely used today especially in international trade and communication, has become widespread as a common language in the scientific field. Most of the international scientific journal articles are published in English, hence it has started to be seen as a global language for decades. Hovewer one of the main topics in English language teaching in recent years is also the subject of "teaching vocabulary". Many students find that learning words is difficult. thinks. Individuals' vocabulary knowledge skill in the target language is a very important issue as it directly affects the use of it. Words constitute the building blocks of a language. Even from simple request to complex feelings and thoughts are expressed through words. In this regard, teaching vocabulary is considered as one of the basic building blocks of language teaching. The concept of color appears in every object we see in the nature and it affects us emotionally. On the whole the learners are very sensitive to the colors. For this reason colours are used in English teaching materials. In this regard, the use of colors in vocabulary teaching in order to facilitate the learning activities was examined in the study.
\end{abstract}




\section{GİRiș}

Dünyanın iletişim ve bilim dili hâline gelen İngilizcenin bilinmesi günümüz şartlarında artık önemli bir ihtiyaç olarak görülmektedir. Demirel'in (2019) de bahsettiği gibi iletişim kurma ihtiyacı, İkinci Dünya Savaşı sonrası bilim ve teknikteki hızlı ilerleme ve gelişmeler, ekonomik, sosyal ve kültürel ilişkiler en az bir yabancı dil bilme gerekliliğini doğurmuştur. Günümüzde özellikle uluslararası ticarette çok yaygın olarak kullanılmakta olan İngilizce, bilimsel alanda da ortak dil olarak yaygınlaşmıştır. Uluslararası kabul görmüş birçok bilimsel dergi makalelerini İngilizce yayımlamaktadır. İngilizce artık küreselbir dil olarak görülmeye başlanmıştır.

Gün geçtikçe ilerleyen ve daha fazla iletişime ihtiyaç duyulan günümüz modern dünyasında, toplumların birbirine köprüler kurmasına imkan sağlayan etkenlerin başında yabancı dil gelmektedir. Dünyadaki insanlar arasında iletişim, bire bir, yakından, uzaktan sözlü ya da yazılı olarak gerçekleşebilir bu da ancak yabancı bir dil kullanılarak mümkündür. Dili tanımlayacak olursak; "Dil, İnsanların duygularını ve düşüncelerini belirtmek için kullandıkları, sözcüklere dayalı anlatım ve ifadeler içeren hareketler ve işaretlerdir." (Longman-Metro, 2007). Dil, "İnsanların düşündüklerini ve duyduklarını bildirmek için kelimelerle veya işaretlerle yaptıkları anlaşma, lisan, zeban" olarak tanımlanmaktadır (TDK Türkçe Sözlük, 2016).

Dünya üzerinde etkin bir şekilde kullanılan dillerin değişimi ve eğitim ile ilgili politikaların da etkisiyle, yüzyıllardır çok değişik sayıda yabancı diller öğretilmeye çalışılmış bunu sağlamak içinde farklı ögretim yolları ve metotları izlenmiştir. Yabancı dil öğretimi konusunda ülkemizde büyük çaba sarfedilmiş, bu konuda kamusal, özel ve bireysel boyutta zaman, kaynak ve emek harcanmıştır. Yabancı dil olarak İngilizceye odaklanma; 1950'lerin ortalarında Anadolu liselerinin kurulması ile başlamıştır. Buna rağmen, Demirel, (1999) yabancı dil öğretiminde istenen seviyede başarı sağlanamadığını ifade etmiştir. Yine Bayraktaroğlu (2015), "İngilizcenin Türkiyenin orta ve yükseköğretim sisteminde yabancı dil olarak öğretilmesi yıllardır çözülememiştir”, demektedir. İlkokuldan başlayamak üzere üniversite sonuna kadar devam eden yabancı dil öğretim sürecindengeçen bir öğrenci, genel anlamda maalesef hedeflenen düzeyde yabancı dil bilgisine sahip değildir. Yabancı dilde başarılı olan pek çok ülkede yabancı dil öğrenimi için belirlenen sürenin Türkiye'dekinden farklı olmadığı bilinmektedir (OECD, 2018).

\section{YABANCI DİL ÖĞRETİMINDE KELIME}

Yabancı dil edinimi karmaşık bir süreç olup çok zaman ve emek gerektirmektedir. Yeterli seviyede belirli bir dili öğrenmenin yollarını açıklamak amacıyla araştırmaların yapılmış olmasıyla, dil öğretiminde bazı unsurların üzerinde durulması gerektiğini göstermektedir (Brown, 2007). Bireyin adı geçen unsurları kullanma düzeyi, sahip olduğu kelime hazinesi ve bunun kullanımı ile direkt olarak ilgilidir. Kelime hazinesini meydana getiren bileşenler içinde kelime, ifade, deyim ve diğer unsurlar bulunmaktadır (Aksan, 1982), burada kelimenin önemli temel bir faktör olarak karşımıza çıkmaktadır. Bununla ilişkili olarak, deyim ve söylemler çeşitli anlam bağları kuran kelimelerin bir araya gelmesiyle meydana gelmektedir.

Kelime herhangi bir dilin en temel yapıtaşları olduğu söylenebilir. Basit bir ricadan karmaşık bir biçimdeki, ifade, duygu ve düşünceler kelimeler vasıtasıyla anlatılabilir. Bu nedenle kelime eğitim veöğretimi, dil öğretiminde temel unsur olarak sayılmaktadır.

Ana dili ve yabancı dil eğitim ve öğretiminde kelime hazinesini artırmaya ve geliştirmeye dönük araştırma ve çalışmalar üzerinde durulması gereken faktörler arasındadır. Bu konu eğitim ve öğretim programlarında da üzerinde durulan konulardandır.

Gerek bu konuda gerekse diğer konular için öğrencilerin çeşitli değişik duyularına (görsel, işitsel, vb.) hitap etmenin onların ilgi ve alakasını daha fazla çektiği ve bu durumun da onların başarısını artırdığı bilinmektedir. Bu nedenle eğitim-öğretim faaliyetlerinde görsel, işitsel ve diğer araçları kullanmak ve yararlanmak üzerinde durulması gereken bir konudur. Karakaş ve Karaca da (2011) eğitimcilerin dil öğretimini görsel olarak desteklemeye yönelik olarak nesnelere ihtiyaç duyduklarını, buna ek olarak 
resimlerin dil eğitiminde en fazla faydalanılan materyaller arasında olduğunu belirtmektedirler. Kelime öğretiminde gerçek nesnelerden hareket etmek yapılabilecek teknikler arasında yer alır (Uçgun, 2006: 224). Bu uygulama gerçek nesneler olmasa da objelerin fotoğraflarını göstermek şeklinde uygulama yapılabilir. Çalışmalarda nesnelerin, materyallerin değişik özellikleri (renk, biçim, vb.) üzerinde de durulabilir. Nesnelerde olduğu gibi, renklerde kelimelerin yansıttığı anlamlarla ifade edilir (Şahin, 1998).

\section{PROBLEM}

Küreselleşen dünyada bilgi toplumu için gerekli özelliklerden birisi de yetkin bir yabancı dil bilgisidir. Her dilde olduğu gibi İngilizceyi etkili bir şekilde kullanmak için çok sayıda kelime bilmek gerekir.

Yabanc1 dil öğretiminde en büyük sorunlardan birinin kelime öğretimi olduğu bilinmektedir,(Brown 2001; Thornbury, 2002; Schmitt, Schmitt, ve Mann, 2011; Rahmawati, 2015). Öğrenciler genel olarak kelime öğrenmenin zor olduğunu düşünmektedir. Öğrenciler kelimeleri bir liste hâlinde çıkartıp onları okuyarak, telaffuz ederek, anlamlarına, eş anlamlılarına bakarak öğrenmeye çalışmakta ve birkaç saat sonra da çalışma sonuçlarından dolayı hayal kırklığına uğrayabilmektedirler. Sonra da hafızalarının zayıf olduğunu düşünerek, İngilizcede çok fazla sayıda kelime olduğuna ve hepsinin de farklı kullanımlara sahip olduğuna inanmaya başlayabilirler.

Kelime öğretiminde öğrenci motivasyonu ile ilgili, Spaulding (1992), kelime öğretiminin öğrencinin isteğini kırabileceğini ifade etmektedir. Günümüze değin Kelime öğrenmenin motivasyonu azaltıcı bir iş olduğuna inanan bazı araştırmacılar kelime öğretimi için geleneksel yöntemler yerine uygulayabilecekleri ve öğrencilerin yararlı olabilecek yöntemler aramaktadırlar. $\mathrm{Bu}$ arayışın sonucunda, renk, resim, müzik, çizim ve hayal gücü kullanılan pek çok farklı strateji ortaya konulmuştur.

\section{YÖNTEM}

Çalışmada Literatür taraması yapılmıştır. Demirci'ye (2014) göre Literatür taraması akademik çalışmalar için çok önemli bir husustur. Literatür taraması ile araştırmanın konusu ile ilgili daha önce yayınlanan kitap, makale, tez, kongelerde sunulmuş bildirile vb., yayınlar aranarak, bulunur, detaylı bir biçimde incelenir. Bu yolla araştırmaya katkı sağlayabilecek bilgilerin elde edilmesine gayret edilir. Literatür taramada temel amaç araştırma konusu ile ilgili gereksinim duyulan bilgilerin elde edilmesini sağlamaktır.

\section{RENK KAVRAMI}

Gündelik hayatımızda rengi sadece görme duyusunu kullanarak algılabilir. Gökaydın (2003:124), düzeni oluşturan (görsel etki) elemanlarının arasında yer verdiği "renk" kavramı için; insanın görsel algısı, doğası 1şının belirli değerlerine karşı duyarlı olduğunda, algılanan nitelik çeşitliliği olarak tanımlamaktadır. Doğada bulunan bütün renkler ana renklerden doğmaktadır. Bunların içerisine olmayan renk olan siyah ve beyaz, bir cismin güneş ışığında depolanmış renkleri, yansıtmayıp da yutuyorsa siyah, bütününü yansıtıyorsa beyaz renk olarak görünmektedir.

Yılmaz (2010: 31-32), görsel tasarım ve düzenleme unsurları olarak yer verdiği renk kavramını, algılanabilmesi için 1şığın varlığına ihtiyaç duyulan, 1şığın cisimlere çarpması ile yansıyan 1şınların gözümüzde oluşturduğu her türlü duyum olarak ifade etmiştir.

Baytekin ve Say, (2003: 36-49) renk kavramının; beyin tarafindan algılanması ve ruhsal etkisi (psikolojik), ışığın göze gelmesi (fiziksel) ve 1şı̆̆ın karşısında gözde oluşan işlemleri (fizyolojik) olmak üzere bu üç şekilde algılandı̆̆ını belirtmektedirler.

Renk kavramı doğada gördüğümüz her nesnede karşımıza çıkmakta ve duygusal olarak bizi etkilediği gibi duygularımızı anlatmada da bir araç olarak kullanılmaktadır. Özellikle Görsel zekâya sahip bireyler başta olmak üzere öğrenciler, renklere karşı hassas ve duyarlıdır. Bu sebeple derslerde renkli materyallerden yararlanılmalıdır. uradan yola çıkarak kelime öğretiminde renklerin kullanımı bu çalışmada incelenecektir. 
Renklerin insan sağlığı ve bedeni üzerine çok büyük bir etkisi vardır. Çalışma ortamının huzur veren, olumlu yönde etkileyen bir renkte olması bile öğrenim açısından son derece önemlidir. Bazı renklerin eksikliği fiziksel ya da duygusal sorunlara da yol açabilmektedir. Dersliklerin duvarlarının, perdelerinin ve hatta öğretmenin kıyafetinin rengi öğrencileri rahatsız edici ya da sakinleştirici olabilmektedir.Sıklıkla kullanılan renklerin özellikleri aşağıdaki gibidir:

Yeşil: Yeşil dengeyi, doğa ve diğer insanlarla uyumu sembolize eder. Sinir sistemini rahatlatır. Umut ve huzur hislerini uyandırır. Yeşilin sabırlı, açık görüşlü ve sessiz gelenekçiler tarafından kullanıldığı söylenir. Ancak fazla yeşil hüzün ve gizli korkuları ortaya çıkartır.

Mavi: Mavi sakinleştirici ve rahatlatıcı bir renktir. Gözler ve zihin için çok rahatlatıcıdır. Entelektüel süreçleri harekete geçirir ve bu yüzden mavi rengi seven insanlar zeki ve çalışkandır ama her zaman yaratıcı değildirler. Maviyi sevenler daha çok sadık, düzenli ve disiplinlidirler.

Sarı: Sarı parlak ve güneş rengine yakın iken sinir sistemini güçlendirir ve bireyleri analitik düşünmeye sevkeder. Bilgelik, hırs, zekilik ve beynin sol kısmı ile ilişkili olan entelektüelliği simgeler. Sarı seven bireyler genelde mutlu ve iyimserdir ama aynı zamanda da eleştirel düşünürler ve kendi düşüncelerini savunurlar. Sarı sevenler yaratıcılık ve hayal gücünden genelde yoksundurlar. Sarının soluk tonları ise diğer yandan kıskançlık, bağımlılık ve entrika gibi rahatsız edici duyguları uyandırır.

Siyah: Siyah gizemi ve bilinmezliği temsil eder. Bireyleri bireysellikten korur ve insanların olağandış1 ve ilginç olanı görmesini sağlar. Siyah seven insanlar farklı şeyler düşünürler ve araştırmayı, keşfetmeyi çok severler.

Turuncu: Turuncu canlılık, iyi bir espri anlayışı ve yaratıcı hayal gücünü simgeler. İnsanların ilham almasına ve canlanmasına yardımcı olur, turuncu sevmeyenlerin depresif, umursamaz ve ilgisiz olduğu düşünülür. Turuncu bu yüzden sosyal dışa dönük bireyler tarafından çok sevilir ve turuncu sevenler neşelenmeye her zaman ihtiyaç duyarlar.

Kırmızı: Kırmızı en etkileyici renklerden biridir ve sağ beyindeki canlı duyguları ortaya çıkartırlar. Sağlık, enerji ve ilgi aşılar. Ancak bazı insanları sinirlendirdiği de düşünülür.

Beyaz: Beyaz gençlik, temizlik ve saflığı simgeler. Beyaz seven insanların mükemmeliyetçi olduğu düşünülür. Gerçekleștirilmesi zor hayaller kuran idealistler beyaz sever.

Pembe: Pembe fazla kullanılmazsa sakinleştirici bir etkiye sahiptir. Hayal kurmayı ve iyimserliği simgeler. Güven duygusuna ihtiyaç duyan hassas insanlar pembeyi sever.

\section{SONUÇ}

Öğrencilerin kelime anlamlarını okuyup kelimelerle ilgili çizimler yaptıklarında o kelimeyi daha iyi öğrendikleri ve sadece kelime ile tanımını yazmanın çok etkili olmadığı bilinen bir gerçektir. Bir tanımın resmini çizmek ve o kişinin zihninde kelimenin karşılığını oluşturmak sadece okumaktan çok daha etkilidir.

Renkleri kullanmak da pek çok farklı konuda benzer sonuçlar doğurur: öğrenciler renklerle çalıştığında daha kolay konsantre olur, bir kelimeyi okurken daha fazla vakit geçirir ve öğrenmeyi daha eğlenceli ve zevkli bulur. Renkler öğrenmede ve gözden geçirmede çok etkili olduğundan öğrenci ile öğretmenler bu yöntemi farklı yerlerde kullanabilirler.

Daha ileri seviyedeki öğrencilere İngilizce kelime ezberletirken bu tekniğin kullanımı ile öğrencilerin sözlük kullanırken aradığı ilk temel bilgileri daha kolay görmesi mümkün olabilir: "ilk önce tanıma mı bakacakları, kendi dillerindeki eş anlamlı kelimelere mi, örnek cümlelere mi, eş anlamlılara mı yoksa başka şeylere mi?”, bunları kolayca anlayabilirler.

Tahtada renkli kalem yada tebeşir kullanımının en popüler örnekleri aşı̆̆ıdaki şekilde olabilir:

1. Telaffuz ve heceleme uygulamaları için zor harflerin ya da ses gruplarının (th sesi gibi) altını çiziniz ya da renkli ile yazınız; daha uzun kelimelerde vurgulu sesi işaretleyiniz (gösteriniz); bir metinde size hoş ya da kötü gelen kelimeleri işaretleyiniz; hatırlayamadığınız kelimeleri çiziniz; 
hatırlamanızı ya da okumanızı zorlaştıran kısımları renklendirin; metinde daha iyi hatırlamak istediğiniz yeni kelimeleri belirtiniz.

2. Öğrencilerin dikkatlerini belli kelimelere ve tartışmalara çekmek için: öğrencilerin kendi fikirlerini yaratıcı bir biçimde beyin firtınası yaparak dile getirmelerine izin veriniz; sizin için neşeli / üzücü / iyi / rahatsız edici kelimelerin altını farklı renklerle çiziniz; dersten sonra hatırlamakta zorluk yaşadığınız kolay ya da zor kelimelerin altını çiziniz; metindeki tüm dikkati çekeni / bunaltıcı / en az dikkati çeken kelimeleri işaretleyiniz.

3. Bir kelimenin gramer yapısını hatırlamak için: somut kelimeleri bir renkle soyutları bir başka renkle yazınız; sayılabilen ve sayılamayan kelimeleri farklı renklerle belirtiniz; geçişli ve geçişsiz fiilleri farklı renklerle çiziniz; varsa erkek, dişil ya da nötr anlamlı kelimeleri farklı renklerle yazınız; metindeki farklı kelimeleri (fiil, isim, sıfat, edat, vb.) farklı renklerle yazınız.

4. Morfoloji çalışmaları için: metindeki tüm önek ve sonekleri farklı renklerle yazınız veya altını çiziniz ve ne anlama geldiklerini bulmaya çalışınız; kelimelerin ne ile ilgili olduklarına göre (örneğin, important/önemli, unimportant/önemsiz) farklı renklerle yazınız; ön, kök ve sonekleri farklı renklerle yazınız ve türeterek liste hâline getiriniz, (örneğin; teach, teacher, teaching / understand, understanding, misunderstanding.)

Renkler ayrıca görsel düşünmede çok etkilidir. Renkler sayesinde fikirler birbirinden daha kolay biçimde ayrılabilir ve hafızada tutmak için yaratıcılığımız kullanabilir. Renkler aynı zamanda dikkat toplamada da önemli rol oynar. Ayrıca belirli renkler öğrencileri etkilemede de daha büyük rol oynar. Renklerden kelime öğretiminde faydalanabilmek için hangi rengin ne tür bir güce sahip olduğunu öğrenmemiz gereklidir.

Genel anlamda kelimeler bir dilin yapı taşlarını oluşturmaktadır. Herhangi basit ricadan çok kompleks yapılardaki düşünce ve fikirler vb. kelimeler vasıtasıyla anlatılırlar. Bu nedenle kelime edimini konusu, dil öğretiminin temel yapı taşlarından sayılmaktadır. Ana dil, yabancı veya ikinci bir dil eğitiminde kelime bilgisini geliştirmeye yönelik çalışmalar günümüzde sistemli bir şekilde ele alınmaktadır. Bu konu eğitim ve öğretim plan ve programlarında da üzerinde önenm verilerin hususların başında gelmektedir.özellikle durulan konulardan biridir.

Uçgun (2006) kelime öğretilirken gerçek nesnelerden faydalanılmanın önemi üzerinde durmuştur. Eğitim ve öğretim faaliyetlerinde objelerin, farklı özellikleri (renk, şekil, vb.) katkısı da vurgulamaktadır. Şahin (1998), renklerin nesnelerde olduğu gibi kelimelerin yansıttığı anlamları ifade edilebileceğini belirtmektedir. Kelime ve harfleri farklı renklerle yazmanın dişında öğrenciler renk kodları kullanarak da daha kolay öğrenebilirler (örneğin, kategorisi ve anlamı verilen kelimeler için belirli renkler kullanılabilir); belirli kelime ve kelime kategorileri için seçilen renklerde yazım yapılabilir ve bunlar sınıf içerisinde kullanılan kartlarda, ipuçlarında, posterlerde kullanabilir ya da belirli dergi sayfaları ya da resimlerde geçen kelimeler (örneğin, cinsiyet ya da sayılabilir isimler) kesip yapıştırılarak da öğrenim verimliliği arttırabilir. Öğrencilerin daha zor kelimeleri daha kolay öğrenmesi için renkli tebeşir kullanabilir ya da kelimelerin altına resim veya renkli baz kağıtları yapıştırabilir. Her öğretmenin sınıf ortam ve seviyesi farklı olacağından öğrencilerinin ihtiyaçlarına göre bu aktiviteleri tasarlayıp yaptırabilirler. Renkli kartlar, posterler, tahta üzerine yapıştırılarak dersler eğlenceli ve zevkli hâle getirebilir.

Renklerin dil öğretimine katkısının yanında insan sağlığı ve bedeni üzerinde de çok büyük bir etkileri vardır. Bazı renklerin eksikliği fiziksel ya da duygusal sorunlara yol açabilmektedir, örneğin sınıf ve derslik duvarlarının, perdelerinin ve hatta öğretmenin kıyafetinin rengi öğrencileri etkileyebilmektedir. Genel anlamda çalışmada İngilizce kelime öğretiminde öğrenci başarısı ve motivasyonuna renklerin etkisi bir çok açıdan incelenmiştir. 


\section{KAYNAKÇA}

Aksan, Doğan (1990), Her Yönüyle Dil Ana Çizgileriyle Dilbilim, Ankara.

Bayraktaroğlu, Sinan (2015), Türkiye'de Yabancı Dil Eğitimi, Öztepe Matbaacılık, Ankara

Baytekin, Yusuf ve Say, Balc1-Nuran (2003), Temel Sanat Eğitimi, İstanbul: Ya-Pa.

Brown, H. Douglas. (2001), Teaching by Principle: An Interactive Approach to Language Pedagogy. New York: Longman.

Brown, H. Douglas (2007), Principles of Language Learning and Teaching (15. Bask1). Newyork: Longman.

Demirci, Ali (2014), "Literatur Taraması”, Coğrafya Araştırma yöntemleri, (Ed.Yılmaz Arı ve İlhan Kaya), (1. baskı). Coğrafyacılar Derneği, Balıkesir, s.73-109, ISBN: 978-605-86453-2-5

Demirel, Özcan (1999), Yabancı Dili Öğrenemiyoruz, Erişim tarihi: 20 Eylül, 2020, http://www.hurriyet.com.tr/egitim/anasayfa/6607825.asp?gid=171.

Gökaydın, Nevide (2003), Temel Sanat Eğitimi, İstanbul: Diasan.

Karakaş, Ali ve Karaca, Gülçin (2011), "Yabancı Dil Öğretiminde Resmin Materyal Olarak Kullanımı ve Önemi”, Yaşadıkça Eğitim, s. 109.

Longman-Metro (2007), Büyük İngilizce Türkçe - Türkçe Sözlük. İstanbul: Serhat Yayınları.

OECD (2018). Education at a glance 2018: OECD indicators, OECD Publishing, Paris, https://doi.org/10.1787/eag-2018-en. Temmuz 2020 tarihinde erişilmişstir.

Rahmawati, Irma. (2015), "Problems in Teaching Vocabulary to Young Learners at Aisyiyah Bustanul Athfal 01 Kindergarten Malang" Unpublished Thesis. Department of English Language Education, Faculty of Teacher Training and Education.

Schmitt, Diane, Schmitt, Norbert ve Mann, David (2011), Focus on vocabulary 1: Bridging vocabulary, White Plains, NY: Pearson Education.

Spaulding, Cheryl L. (1992), Motivation in the Classroom, New York: McGraw-Hill.

Şahin, Ebru (1998), “Color Naming”, A Doctoral Thesis, Submitted to the Department of Interior Architecture and Environmental Desing and the Institute of Fine Arts of Bilkent Universtiy in Partial Fulfiilment of the Requirements for the Degree of Ph.D. In Art, Desing and Architecture, Ankara.

TDK Türkçe Sözlük. (2016), Güncel Türkçe Sözlük, Türk Dil Kurumu, Ankara. Web: http://www.tdk.gov.tr/index.php?option=com_gts\&kelime=dil adresiyle, 20 Temmuz,. 2020 tarihinde erişim sağlanmıştır.

Thornbury, Scott (2002), How to Teach Vocabulary. London: Longman.

Uçgun, Duygu (2006). "Yabancılara Türkçe Öğretiminde Sözcük Dağarcığını Geliştirme Teknikleri”, Türklük Bilimi Araştırmaları. S. XX, s.217-227.

Yılmaz, Meliha (2010), Görsel Sanatlar Eğitiminde Uygulamalar, Ankara: Data. 